\title{
PRÁTICAS HOMOSSEXUAIS EM AMBIENTES PÚBLICOS DO INTERIOR DO RS: ESPAÇOS DA SEXUALIDADE EM MICROTERRITÓRIOS
}

\author{
HOMOSEXUAL PRACTICES IN PUBLIC ENVIRONMENTS IN \\ THE RS COUNTRYSIDE: SEXUALITY SPACES IN \\ MICROTERRITORIES
}

\begin{abstract}
Liziany Müller ${ }^{1}$
Gabriella Eldereti Machado ${ }^{2}$

Ivanio Folmer ${ }^{3}$

\section{RESUMO}

Este texto tem como objetivo analisar o surgimento de um microterritório, segundo a relação entre sujeitos conectados a partir da identidade, no caso deste estudo, os homossexuais. Percebendo desta forma a trajetória social que esses sujeitos passaram e passam. Para tal, foi feito um estudo de relação entre o conhecimento geográfico e psicológico, na tentativa de associar este novo território com causas expressadas a partir das relações sociais historicamente acumuladas que estes sujeitos vivenciaram. A priori, esta pesquisa foi uma elaboração através de leituras sobre este tema, por autores que já contribuíram para o crescimento deste debate. Neste texto, chegamos ao entendimento de que se é necessário maiores pesquisas em torno destes sujeitos, a fim de que surjam melhores condições de saúde integral, bem como construção de políticas que fortaleçam as boas relações humanas.
\end{abstract}

Palavras-chaves: Território; Gênero; Homossexuais.

\begin{abstract}
This text analyzes the emergence of a micro territory, based on the relationship between individuals connected by their identity. In the case of this study, we analyze homosexuals, observing their social trajectory. To this end, a study of the relationship between geographic and psychological knowledge was conducted to associate this new territory with causes expressed from social relations historically accumulated that these subjects experienced. A priori, this research was elaborated through readings by authors who have already contributed to this debate. In
\end{abstract}

\footnotetext{
1 Atualmente é Professora da Universidade Federal de Santa Maria. Doutora e Mestra pelo Programa de PósGraduação em Agronomia da Universidade Federal de Santa Maria. e-mail: lizianym@hotmail.com

${ }^{2}$ Atualmente é Doutoranda e Mestra em Educação pelo Programa de Pós-Graduação em Educação da Universidade Federal de Santa Maria. Licenciada em Química pelo Instituto Federal de Educação, Ciência e Tecnologia Farroupilha - IFar - Campus Alegrete. e-mail: gabriellaeldereti@gmail.com

3 Atualmente é Doutorando e Mestre em Geografia pelo Programa de Pós-Graduação em GeografiaPPGGEO/UFSM. Licenciado em Geografia pela Universidade Federal de Santa Maria. e-mail: ivaniofolmer@yahoo.com.br
} 


\section{Revista \\ Debates Insubmissos}

this text, we come to understand that further research is needed on these subjects for better integral health conditions to emerge and the construction of policies that strengthen good human relations.

Keywords: Territory; Genre; Homosexuals.

\section{INTRODUÇÃO}

Neste texto, refletiremos sobre a relação do surgimento de um microterritório no espaço geográfico a partir da utilização do grupo social: "indivíduo auto identificado como homossexual". Salientamos que no grupo social descrito, fazem parte não somente pessoas que se relacionam com pessoas do mesmo sexo por prazer e afetos mútuos, como também por outros interesses. Este trabalho foi construído na perspectiva do conceito de territorialização a partir do uso do espaço no qual estes sujeitos estão inseridos no ambiente urbano de cidade do interior. As análises apresentadas na revisão bibliográfica foram extraídas de documentos como livros, teses, dissertações e outras publicações que abordam assuntos relacionados à temática do território da cidade e suas relações com as questões de gênero, sexualidade e práticas sexuais.

São utilizados conceitos geográficos e psicológicos para a discussão, interpretação e descrição dos territórios homossexuais analisados, visto que as vulnerabilidades e o comportamento sexual de homens e mulheres são formatados pelas normas e papéis de gênero (LOPES E GOMES, 2013). O ideário sociocultural de como o homem deveria se sentir e agir dentro da cultura do machismo, apesar das mudanças e tendências ocorridas nos últimos anos no mundo, constituem ações institucionalizadas recorrentes. Vários modelos enraizados de leitura das práticas sexuais têm validado e mantido um tipo de organização social, ao defenderem uma única forma de viver a afetividade "moralmente adequada ou mais saudável", centrada no paradigma religioso ou na moral de saúde. Esta frequentemente definida como a relação heterossexual, de afeto e interesse sexual entre indivíduos de diferentes gêneros. Este conjunto de normas comportamentais exclui uma grande faixa da população, especialmente aquelas com sentimentos e desejos distintos destes prescritos pela norma (MOITA, 2006).

Neste sentido, torna-se especialmente importante conceber a organização que se estabelece entre a sociedade, a distribuição e a ocupação dos espaços urbanos, visto que ela é 
representativa da dinâmica social. Essa organização pode ser melhor exemplificada pela relação entre os grupos e os locais reservados para práticas sexuais de homens auto identificados como homossexuais e locais em que os grupos admitem as práticas de paquera, de "pegação" e de trocas sexuais.

Essa distribuição social organiza e é organizada pelos significados de "permitido" e "proibido". Logo, torna-se claro que estas vivências sexuais não correspondem às expectativas sociais de gênero e identidade sexual. Estas, por serem comumente descritas como realizadas em Parques e banheiros públicos, são reservadas de algum modo ao espaço privado, ou melhor, ao escondido, visto seu caráter "pecaminoso", "doentio" e "transgressor" dos primeiros discursos, instituições e definições que a organizaram, como diz Ferrari (2006, p. 13). Lembrando que este estudo se propõe a amplificar o olhar territorial e psicossocial sobre estes fenômenos. Estes locais de conquista e de envolvimentos sexuais, no entanto, passam desapercebidos por muitos habitantes.

Sendo assim, nesta condição, descarta-se a utilização de um entendimento moral comumente atribuído a elas e uma possível concepção errônea de que estas práticas já partiriam de algum sintoma patológico. Por outro lado, ao serem reveladas estas práticas nestes espaços frequentemente se notam posicionamentos que tendem a patologizar a Homossexualidade, entendendo estas ações com julgamentos morais que as reduzem a efeitos nocivos desta orientação.

\section{O QUE ENTENDEMOS POR TERRITÓRIO?}

É necessário ter o entendimento amplo da dinâmica espacial dos territórios, para que se possa compreender como ocorre a interação de indivíduos, de classes e de fenômenos, bem como os eventos que ocorrem neste. Sendo importante ressaltar o panorama atual da questão homossexual na sociedade brasileira para que se entenda o histórico deste grupo, da forma em que se perceba a situação política relacionada às lutas da comunidade, para que, por fím, possa ser reconhecida a necessidade da implementação de políticas associadas à causa destes sujeitos historicamente segregados. 


\section{Revista \\ Debates Insubmissos}

A compreensão do conceito território é fundamental para que seja esclarecedor o entendimento das transformações e territorializações no espaço quanto ao assunto dos homossexuais nos contextos de cidades do interior. Quando o termo território surge, o mesmo se conecta aos movimentos de poder, não retratando apenas as questões de poder voltado à demanda política, como também ao sentido simbólico de apropriação do poder (Haesbaert, 2004), ou seja, como menciona Souza (2009, p.59) que "o que 'define' o território é, em primeiríssimo lugar, o poder - e, nesse sentido, a dimensão política é aquela que, antes de qualquer outra, lhe define o perfil”.

Além de todas as acepções, o território, conforme Santos (2002, p.9), "é o lugar em que desabrocham todas as ações, todas as paixões, todos os poderes, todas as forças, todas as fraquezas, isto é, onde a história do homem plenamente se realiza a partir das manifestações de sua existência". Entendendo o claro argumento de que "não há como definir o indivíduo, o grupo, a comunidade, a sociedade sem ao mesmo inseri-los num determinado contexto geográfico, 'territorial'” (HAESBERT, 2004, p.20).

Deste modo, “a apropriação e produção do espaço geográfico, cotidianamente, estão na base do arranjo territorial. Território e espaço estão ligados, entrelaçados, pois o primeiro é fruto da dinâmica socioespacial" (SAQUET, 2005, p. 49). O Espaço e o Território estão em contínua transformação diante das relações que são estabelecidas pelo homem e suas relações, sendo assim são expressas diferentes temporalidades e territorialidades.

Tratando ainda sobre o conceito de território, Ratzel contribui para o pensamento geográfico e as ciências humanas, ressaltando que os "organismos que fazem parte da tribo, da comuna, da família, só podem ser concebidos junto a seu território" (RATZEL, 1990, p. 74), como também, "do mesmo modo, com o crescimento em amplitude do Estado, não aumentou apenas a cifra dos metros quadrados, mas, além disso, a sua força, a sua riqueza, a sua potência" (RATZEL,1990, p. 80). Fica evidente na ideia do autor que o território é um espaço necessário para a população evoluir.

De modo a contrapor as ideias de Ratzel, Raffestin inicia sua tese percebendo que "o quadro conceitual de Ratzel é muito amplo e tão naturalista quanto sociológico, mas seria 


\title{
Revista \\ Debates Insubmissos
}

errôneo condená-lo por ter "naturalizado" a geografia política, algo que às vezes ocorreu." (RAFFESTIN, 1993, p. 2). Desta maneira, a proposta de Raffestin é repensar o conceito de território deixado por Ratzel. Para o autor,

\begin{abstract}
É essencial compreender bem que o espaço é anterior ao território. O território se forma a partir do espaço, é o resultado de uma ação conduzida por um ator sintagmático (ator que realiza um programa) em qualquer nível. Ao se apropriar de um espaço, concreta ou abstratamente (por exemplo, pela representação), o ator "territorializa" o espaço (RAFFESTIN, 1993, p. 50)
\end{abstract}

A intencionalidade de Raffestin (1993) em relação ao território se direciona para além das concepções biológicas da expressão, sendo o conceito que envolve poder o impulsionador da modificação do espaço, pensando que "o território se apoia ao espaço, mas não é o espaço. É uma produção, a partir do espaço. Ora, a produção, por causa de todas as relações que envolvem, se inscreve num campo de poder" (RAFFESTIN, 1993, p. 51).

A territorialidade é expressão do comportamento vivido, incluindo a relação do território e o espaço externo, englobando aquilo que fixa o homem aos lugares e ou o coloca para fora do território. Essas questões envolvem a definição de um espaço cultural, sendo entendida:

[...] como espaço geossimbólico, carregado de afetividade e significações: em sua expressão mais forte, torna-se território-santuário, isto é, um espaço de comunhão com um conjunto de signos e valores. A ideia de território fica associada à ideia de conservação cultural. (BONNEMAISON, 2002, p. 111).

Para Sack (1986), a territorialidade nos humanos é algo enraizado social e geograficamente, estando relacionada à maneira com que as pessoas usam o meio e organizamse no espaço, dando sentido ao lugar. A territorialidade é a utilização do espaço de forma equilibrada historicamente, consciente da inter-relação da sociedade e o espaço. De acordo com Raffestin (1993), a territorialidade reflete a perspectiva de multidimensionalidade do vivido territorial por membros de uma coletividade social. Diante disso, cabe dizer que são as relações de poder que se estabelecem entre os atores sociais, onde está influenciado o contato da sociedade e natureza.

Por vez, a territorialidade vem a somar em um conjunto de relações que se estabelece diante de um sistema que integra três dimensões: sociedade, espaço e tempo. Onde se busca a 
implantação da autonomia de um sistema, que para Andrade (2004), a territorialidade advém da consciência que as pessoas que habitam um território têm sua participação na formação histórica deste, que se dá de forma subjetiva.

De acordo com o que foi conceitualmente construído, podemos associar a territorialidade como próprio conceito de território, baseando-se em suas relações sociais expressas nas atividades cotidianas, produzindo valores e funções aos instrumentos espaciais. Quando há construções de referências simbólicas e identitárias que contemplam a identificação de um grupo, sendo assim, tratado como territorialização. De modo contrário a desterritorialização, que significa o desarraigamento de povos, atividades sociais e econômicas que envolvem a comunidade, como uma perda de cultura que outrora estava ligado àquele espaço.

A territorialização preenche o movimento de reconstrução dos laços de identidade com novos atores sociais agindo no contexto territorial. Segundo Haesbaert (1999), uma das marcas centrais do movimento de desterritorialização moderno e globalizado seria a produção de aglomerados, símbolos da chamada "desterritorialização extrema" e "precária", que nos trazem a perspectiva de uma massa disfuncional sem identidade e espacialmente definida por um ponto, linha ou superfície.

Há também uma terceira modalidade, mais recente, nomeada de micro territorialidade, segundo Fortuna (2012), a micro territorialidade seria uma modalidade de socialização articulada com valores, subjetividades e afetos, reconhecendo formas de organização social não institucionais e transformações radicais de valores e estilos de vida. A micro territorialidade é a interpretação de eventos que motivam ações territoriais, que se nota na concretização de estilos de vida urbanos. Turra (2003) fala sobre o movimento punk em Londrina, de forma em que ele está se referindo a um tipo específico de identidade cultural expressa em um território. Diante disso podemos associar o movimento que une dois homens auto identificados como homossexuais, como o surgimento de um território homossexual.

\section{O SURGIMENTO DE UM TERRITÓRIO HOMOSSEXUAL: MICROTERRITORIALIDADE OU SEGREGAÇÃO?}




\section{Revista \\ Debates Insubmissos}

Neste sentido, analisamos no presente texto a contextualização do território homossexual, tentando entender como se cria este microterritório, problematizando e entendendo as razões do surgimento. Previamente, podemos considerar diante do que foi percebido, que os territórios ocupados por homossexuais são flexíveis e móveis, o que nos faz crer que há fatores segregacionistas dentro da espacialidade da cidade.

Por este viés, conforme Pinós (2013), a territorialização segue no sentido de apropriação dos elementos do espaço, nomeados e representados, mas também um jogo de disputas internas entre agentes de uma comunidade que culminam na desigualdade de domínios das riquezas, onde o principal agente é o sujeito social homossexual, que historicamente sofre pela desigualdade implicada a partir das expectativas de gênero e orientação sexual.

Entendemos que cada indivíduo que compõe a sociedade possui características impares, construindo assim sua própria formação social, onde está imbricada uma série de identidades, que se criam a partir de inúmeros fatores, articulando-se com as questões biológicas e culturais, cabendo dizer, inclusive, as escolhas deste indivíduo. Entendendo que homens e mulheres são sujeitos sociais, os mesmos criam expectativa e reproduzem no espaço suas características, desta forma a(s) identidade(s) é/são o que une pessoas em um grupo. Para tal, Maffesoli (1995) chama como "ressurgimento comunitário", adaptamos sua interpretação como o surgimento de um microterritório, por se tratar de uma socialização articulada.

Referente ao preconceito sofrido pelos homossexuais, chamado de homofobia, apesar de também considerarmos o termo heterossexismo como um representante destes fatos e atos. A homofobia é um termo criado pelo psicólogo George Weinberg na década de 1970, onde o mesmo se volta à aversão, ou medo de homossexuais. No entanto, em termos de adequação com estudos recentes, vamos adotar o termo preconceito contra a diversidade sexual e de gênero.

Neste sentido, Herek (1994) afirma que, com o surgimento do termo homofobia, houve um momento de grande influência nas ciências sociais sobre a orientação sexual, tendo a concepção de que não mais era o homossexual a "estar doente", e sim o sujeito que continha preconceito contra ele. Atualmente, a homofobia deixa de ser individualizada e é reconhecida 


\section{Revista \\ Debates Insubmissos}

como um fenômeno social, construído a partir de crenças sociais distorcidas derivadas de inúmeros fenômenos, e reforçadas pelos discursos e ações cotidianas desqualificadoras desta orientação. O preconceito contra a diversidade sexual e de gênero, portanto, é uma atitude derivada de construções sociais a respeito de orientações sexuais não-heterossexuais. $\mathrm{O}$ heterossexismo representa traços semelhantes ao racismo e o sexismo, e descreve um sistema baseado em três esferas: ideológica, social e institucional. Através disso coloca qualquer expressão sexual abaixo da heterossexualidade, no qual resulta em uma perspectiva de que todas as pessoas seriam heterossexuais.

Há também a necessidade de se considerar que ainda existe a falta de informação, que por sua vez vincula a discriminação contra este grupo social. O exemplo disso é a ligação desses sujeitos com a AIDS, doença que já foi chamada de "câncer gay", período este de grande surto na década de 1980, em grande parte dos infectados eram homossexuais. Neste momento, não podemos deixar de lado a grande influência de algumas religiões ${ }^{4}$, que consideram a homossexualidade como algo derivado de forças malignas, e acomete alguns sujeitos a não exercerem suas expressões de gênero, por medo de retaliações públicas e ou divinas.

Portanto, esses dentre outros muitos outros fatores fazem com que o sujeito homossexual seja diariamente ofendido por algum tipo de discriminação explícita ou implícita. Favorecendo o não desenvolvimento de sua identidade em toda a plenitude possível de saúde, por nutrir vários medos e ansiedades que alternam em diversas escalas, desde um pai que não aceita o filho ou filha homossexual até o infeliz hábito de ouvir uma série de ofensas naturalizadas nos discursos e outros atos de violência aos gays. Na política e na mídia em geral, são vistos poucos representantes homossexuais, o que nos leva a crer que há grande desmotivação e aceitação desse grupo nestes espaços, que acabam por elevar a desnaturalização desta orientação.

\footnotetext{
${ }^{4}$ De forma muito geral, podemos afirmar que as grandes religiões monoteístas são as que mais impõem dificuldades para a aceitação da diversidade sexual, mas em maior ou menor grau, todas as religiões tradicionais do mundo demonstram algum nível de rejeição ou preconceito, mesmo quando apresentam um discurso aparentemente não excludente (SWIDLER, 1993).
} 
Esses fatos levam o sujeito a não expor suas identidades sexuais, ou seja, muitos desses indivíduos não assumem suas sexualidades nos espaços de interação social legitimados, tão pouco para seus núcleos familiares. Desta forma, a revelação da orientação sexual, deixa o indivíduo gay passível de perda das conexões humanas (familiares e amigos), visto que é gradativo o número de eventos negativos por parte da sociedade (discriminação, rejeição, abuso físico ou verbal). Deste modo, este grupo "enfatiza as estratégias de atuação para esconder a realidade ou, do outro lado, buscam dar dicas de como obter apoio social para resistir à hostilidade advinda da revelação da orientação sexual” (VINCKE \& BOLTON, 1994, p. 1050).

Este fato não significa que esses sujeitos não passam pelo processo autorreconhecimento de suas identidades, onde eles procuram dividir com outros (que passam pelo mesmo processo, ou algo semelhante) a fim de encontrar o seu semelhante, para isso, esse sujeito utiliza-se de expressões simbólicas que sejam capazes de provocar no outro a identificação de si. Da mesma forma, Pinós (2010) afirma que,

A microterritorialização institui a relação sociedade-indivíduo-espaço e expressa a cultura ou as práticas - interações corporais (ações, gestos, condutas, jeitos e acessórios corporais) estabelecidas - e representações - ideias e identificações sobre o eu e os outros - dos sujeitos orientados para o mesmo sexo. (PINÓS, 2010, p. 3).

A partir desses dois pensamentos, pontuamos o surgimento de um microterritório organizados em símbolos de reconhecimento como: a fala, as vestes, a música, artefatos e imagens, dentre outros muitos que variam conforme o local. Desde muito cedo são atribuídos estereótipos que se agarram firmemente ao sujeito, favorecendo o reconhecimento em determinado grupo social, como também a causa de discriminação por uma camada da sociedade.

Diante do preconceito, é possível perceber um movimento que vai contra isso, o que podemos chamar aqui de identidade homossexual, que vem se tornando um grupo que ganha mais espaço, difundindo-se através de símbolos e imagens, em que são percebidos até mesmo por pessoas que não se identificam com o gênero em questão. De certo modo, isso se dá pela amplificação midiática e por fazer parte do cotidiano das pessoas. Ainda é fácil afirmar que 
estamos muito longe de uma sociedade no qual os homossexuais sejam aceitos pela sua orientação sexual tal como os heterossexuais.

Logo, como foi visto a partir das interações com o universo onde vivemos, presenciamos preconceitos de vários tipos. Acreditamos na existência de padrões hierárquicos, onde o sujeito que recebe a valorização, infelizmente ainda é o que carrega as seguintes características: Homem; Cisgênero (que se identifica com o Gênero que lhe foi atribuído); Branco; Rico e Heterossexual. Os demais que fogem desse padrão são desqualificados, como se não pudessem circular por espaços públicos. Como se não fossem dignos de direitos básicos como respeito, por ser de outro gênero, orientação sexual, classe social ou cor. Os homossexuais são um dos grupos mais acometidos pela irracionalidade que cega e faz com que se criem tabus tão difíceis de desconstruir na sociedade.

Pensamos que esse microterritório que surge é por sua vez resultado de toda essa hierarquização que anula e invalida este sujeito, e, então, os obriga a buscar em um espaço a complementação daquilo que não encontram na sociedade, e neste lugar eles podem ser, agir e sentir de maneira livre o que são.

\section{PRÁTICAS HOMOSSEXUAIS INTERIORANAS: DISSIDÊNCIAS DE GÊNERO EM QUESTÃO}

Discute-se neste trecho as questões relacionadas ao entendimento das práticas homossexuais em cidade de interior, a partir, inicialmente, de perspectivas de gênero pelo viés decolonial, através dos estudos de Connell (2016). No qual, Connell (2016) descreve que gênero é compreendido como um assunto que carrega certa esquisitice, pois é uma questão de experiência do cotidiano, envolvendo assim, toda a população. Desse modo, gênero é definido como:

Compreendendo o gênero primariamente como uma estrutura, uma dimensão central de nossa vida social. O gênero pode, claro, ser definido de muitas formas: como um papel, uma identidade, uma formação discursiva, uma classificação dos corpos, e outras mais. Mas o que faz com que qualquer uma delas tenha importância para o mundo é o que podemos fazer coletivamente com essas identidades e classificações.

(CONNELL, 2016, p. 16-17). 


\section{Revista \\ Debates Insubmissos}

A perspectiva de Connell contribui para entendimento de questões relacionadas a produção dos corpos, corpos heterossexuais, homossexuais, e corpos desviantes. Ao observar esses aspectos no contexto do interior, ainda questões do corpo encontram-se atreladas ao estereótipo de homens gays "aceitáveis", ou seja, que não são afeminados. Essas questões são explicadas, segundo Connell, da seguinte maneira:

É certamente verdadeiro hoje em dia que nossos corpos são produzidos, crescem, desenvolvem-se ou são danificados, e eventualmente morrem, em ambientes sociais fortemente estruturados. O gênero, pode-se dizer, é especificamente uma questão de corporificação social. (CONNELL, 2016, p.17).

Esse entendimento permeia também a discussão sobre a masculinidade instituída aos homens, sejam eles hétero ou gays, sendo um elemento significativo para compreensão das relações homossexuais observadas no cenário do interior. Desse modo, mencionam-se "masculinidades" no contexto de gênero, sendo o termo definido como:

As masculinidades são padrões socialmente construídos de práticas de gênero. Esses padrões são criados por meio de um processo histórico com dimensões globais. A pesquisa "etnográfica" à moda antiga, que situava os padrões de gênero puramente em contexto local, não condiz com a realidade. (CONNELL, 2016, p. 94).

Com isto, os processos de masculinidades constituem experiências sexuais e não sexuais de homens, em contextos de grupos e comunidades de encontros e relações, permeadas pela performance de gênero. Sendo este processo destacado por Connell (2016, p.139) da seguinte forma, "Como as masculinidades são configurações de práticas associadas com a posição social dos homens, as histórias de vida dos meninos são o principal lugar social da construção da masculinidade".

No contexto do interior o que se sobressai em relação a sexualidade é a representação de uma heterossexualidade compulsória, com base no pensamento hegemônico e patriarcal. Sistema esse que alia significações de gênero e desejo e as relações entre os corpos em sociedade. Ressaltando o conceito de biopoder que Foucault defende, e nos estudos de Peres e Toledo é explicitado da seguinte forma:

Portando, no âmbito da sexualidade, o biopoder é aquele que será responsável pela disciplinarização dos corpos e pela regulação dos prazeres, de modo que todos se voltem para a heterossexualidade e correspondam aos padrões de gênero e de desejo socialmente determinados para seu sexo biológico. Seguir a heteronormatividade é considerado pelas práticas discursivas das ciências, bem como da maioria das 


\section{Revista \\ Debates Insubmissos}

religiões e das tradições culturais, como algo natural, normal, correto, santificado, saudável e superior às outras formas de sexualidade. (PERES; TOLEDO, 2011, p. 264).

Desse modo, os homens gays em contexto do interior atuam em performances heterossexuais, visto o resultado da influência do sistema biopolítico sobre esses corpos, como menciona Peres e Toledo (2011, p. 266) “A ideia de tomar os estigmas como processos ampliam as possibilidades de análises sobre o próprio estigma, pois o tomamos como efeito do biopoder e suas biopolíticas que atua sobre os corpos e suas relações, de modo a torná-los dóceis, úteis e assépticos".

O entendimento dessas relações entre homens no interior também passa pela personalização de um personagem, como discute Miskolci (2013, p. 311) "A “masculinidade" é, portanto, negociada e imaginada diferentemente segundo o contexto e a origem sociocultural dos envolvidos". A partir dessa personificação de uma masculinidade heroica os homens homossexuais constituem uma cultura interiorana de relações de gênero e sexualidade gay. Como ressalta Miskolci:

Ainda que afirmem a importância das relações homoeróticas em suas vidas, vivem relegando-as ao segundo plano. Essa maneira de organizar suas relações parece contradizer seus discursos, mas um olhar mais atento pode perceber que, mesmo mantidas em segredo e ocupando menos tempo em sua vida cotidiana, as relações secretas realmente desempenham um papel fundamental para eles. Marcados por uma concepção de masculinidade com fortes raízes históricas na sociedade brasileira, sentem-se mais integralmente homens quando vinculam à relação oficial com a parceira uma outra. No entanto, nesse caso a outra é um homem, o que modifica os termos de negociação do segredo. Exercitando uma masculinidade culturalmente reconhecida com outro homem no lugar da amante, passam da afirmação de sua virilidade para o risco de vê-la contestada. (MISKOLCI, 2013, p. 313).

O elemento "armário" no espaço de cidades do interior é compreendido como um regime de controle dentro do sistema biopolítico. Que é incorporado de forma subjetiva quando se observa que as relações sexuais entre homens acontecem e existem, porém, em espaços "escondidos" das cidades do interior. Visto a concepção de masculinidade hegemônica como sendo heterossexual, os homens do interior sentem esse sistema quando performam masculinidades de "verdade", vivendo sua sexualidade no armário em espaços reservados e escondidos da cidade. 
Revista

Debates Insubmissos

\section{METODOLOGIA E ANÁLISE}

Em relação a metodologia, as saídas de campo, ou pesquisas de campo utilizadas na área da Geografia foram adaptadas, surgindo como resultado a criação da chamada metodologia de "Observação da cidade". A metodologia de saída de campo auxilia na pesquisa e observação do fenômeno estudado, englobando aspectos relacionados à coleta de dados e o registro deles.

As observações foram realizadas na cidade do interior do estado do Rio Grande do Sul, em Santa Maria, localizada na região central. A cidade de Santa Maria, possui cerca de 280.505 habitantes, segundo dados do IBGE de 2018, e está localizada a $290 \mathrm{~km}$ da capital do Rio Grande do Sul, Porto Alegre.

As “observações da cidade" foram divididas em etapas, bem como, a construção teórica desta pesquisa. Sendo assim, segue abaixo a descrição de cada etapa que compõem o estudo:

Quadro 1 - Etapas do estudo

\begin{tabular}{|l|l|}
\hline \multicolumn{1}{|c|}{ Etapa } & \multicolumn{1}{c|}{ Descrição da ação } \\
\hline 1 - Mapeamento e censo. & $\begin{array}{l}\text { Mapeamento de dados referentes ao público LGBTTT } \\
\text { da cidade de Santa Maria. }\end{array}$ \\
\hline 2 - Saídas de observação da cidade. & $\begin{array}{l}\text { Observação em praças, parques e centro da cidade de } \\
\text { Santa Maria. }\end{array}$ \\
\hline 3 - Sistematização. & Organização dos dados observados. \\
\hline 4 - Organização teórica. & $\begin{array}{l}\text { Estudos teóricos e aproximações com os resultados } \\
\text { observados. }\end{array}$ \\
\hline
\end{tabular}

Fonte: Autores (2020).

A partir da organização das etapas da pesquisa, o estudo foi realizado durante o período compreendido do ano de 2017 a 2019. Com isto, são apresentados os resultados referentes ao estudo. Começando com a Etapa 1, temos como base o levantamento de informações feito pelo Coletivo $\mathrm{VOE}^{5}$, através do relatório produzido sobre dados referentes a LGBTfobia na cidade de Santa Maria. Focamos nos dados referentes ao público do estudo, homens gays/homossexuais.

\footnotetext{
${ }^{5}$ O Coletivo Voe é um grupo de ativismo LGBT, criado em 2011, que luta contra o machismo, o racismo e qualquer forma de opressão contra as identificações não heterossexuais ou não cisgêneras. Tais como a homofobia, a lesbofobia, a bifobia e a transfobia. Dentre suas atividades no município, o Voe promove debates, aulas públicas, palestras, festas, espaços de formação, rodas de conversa e a Parada LGBT Alternativa de Santa Maria (UFSM, 2019).
} 


\section{Revista}

Debates Insubmissos

Referente a orientação sexual do público LGBTTT da cidade de Santa Maria, os resultados são:

Gráfico 1 - Orientação sexual

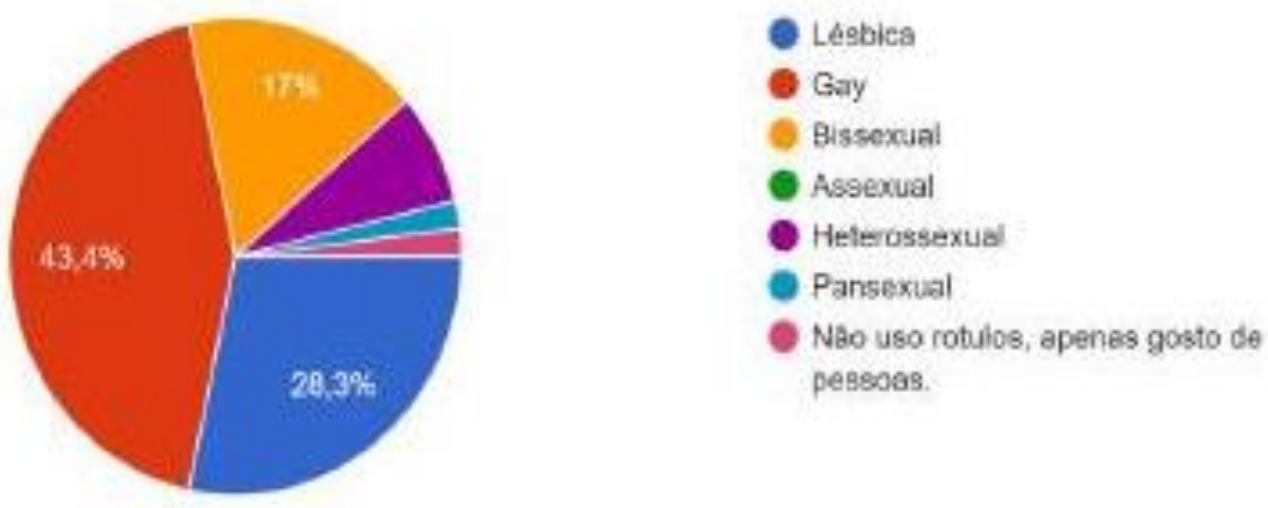

Fonte: UFSM (2019). 


\section{Debates Insubmissos}

Revista

Sobre a identificação de gênero, temos o seguinte gráfico:

Gráfico 2 - Gênero

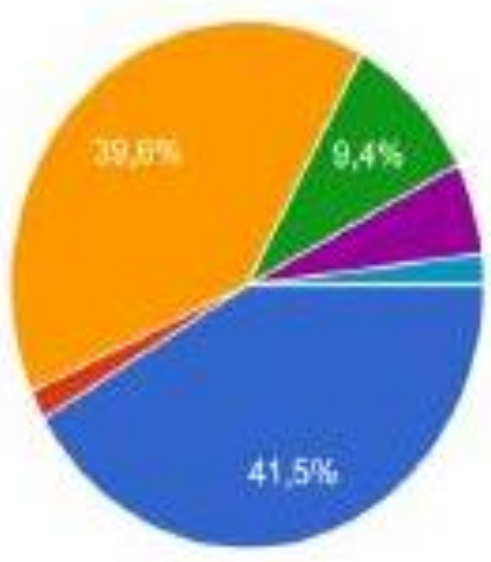

Muiher Cls iMuner que se identifics com o seu generc/sexo bioblogico d.. Mulher Trans (Mulher que náo se identifica com o seu genera'sexo bi. Homem Cis (Homem que se identifica com o seu géneralsexo biolbgieb d. Homem Trans (Homam que năo so identifica com e seu génera'sexo bel Nao-Bviáro /identidade de gènero. Homem

Fonte: UFSM (2019).

Esses dados demonstram resultados referentes a identificação de gênero, observando o público do estudo, em sua maioria identificam-se como homens cis gays. Com isto, na segunda etapa, foram realizadas as saídas de observação da cidade, em locais como praças, parques e calçadão (local central da cidade). Esses lugares foram escolhidos por possuírem o estigma histórico de serem locais onde o público LGBTTT se encontra.

O público observado foi composto de homens cis gays, entre 25 a 40 anos, que costumam estar nos lugares citados anteriormente. No período do estudo não foram feitas entrevistas ou abordagens individuais do público, foram feitas somente observações de suas práticas. Trazendo assim, os resultados desta etapa: o que foi observado é que esses lugares da cidade são locais de encontro de homens cis gays, que performam estereótipo de homens héteros, não afeminados, e que se relacionam em locais "escondidos ou reservados" da cidade com outros homens.

Eles se encontram nesses locais, conversam e ocupam espaços como banheiros públicos, locais afastados em praças e locais escondidos da cidade para práticas sexuais homossexuais. 


\section{Revista \\ Debates Insubmissos}

Foi observado a predominância de uma regularidade do público frequentador aos lugares, sendo praticamente os mesmos sujeitos, em uma rotina quase que diária.

\section{CONCLUSÕES}

Ao longo da escrita do texto, procurou-se entender como se origina um microterritório homossexual, suas razões de formação, identidade e símbolos, para através disso entender como esse microterritório se constitui e quem são os agentes dele. Atingindo com o estudo realizado a compreensão da constituição do simbolismo dentro de uma conjuntura de significações e relações entre significantes e significados (CASTORIADIS, 1982), com o propósito de ser base para a compreensão do imaginário do público observado, permeando as questões do estudo e seus reflexos teóricos e práticos.

Ao dispor do trabalho com a diversidade, presume-se que os (as) pessoas estejam dispostos (as) a atuar em outra lógica, podendo ser caracterizada como uma (des)construção necessária, e, com isto, propor-se a reconstruir o imaginário social de naturalização disciplinar e normatizadora, representadas nas instituições e sociedade. Ou seja, pensar questões contemporâneas por meio do questionamento do modelo instituído, machista, heteronormativo e branco (CÉSAR, 2009).

Ao finalizarmos, gostaríamos de deixar aqui estampado a reflexão sobre esse tema, da mesma forma apontar os inúmeros tipos de preconceitos que existem na sociedade contemporânea. Afirmando que este é o momento de acabarmos com esta postura e que é necessário haver uma ruptura para que possamos viver em uma sociedade mais justa, onde todas as identidades sejam respeitadas, não como um favor e sim como um direito de viver dar vida aos territórios onde circulam.

\section{REFERÊNCIAS}

ANDRADE, Manuel Correia de. A questão do território no Brasil. 2 ed. São Paulo: Hucitec, 2004. 
BONNEMAISON, Jöel. Viagem em torno do território. In: Rosendahl, Z. e Corrêa, R.L.(orgs). Geografia Cultural: um século (3). Rio de Janeiro: EdUERJ, 1981.

CASTORIADIS, Cornelius. A instituição imaginária da sociedade. Paz e Terra: Rio de Janeiro, 1982.

CÉSAR, Maria Rita de Assis. Gênero, sexualidade e educação: notas para uma "Epistemologia". Educar. Curitiba, nº. 35, p.37-51, 2009. Editora UFPR.

CONNELL, Raewyn. Gênero em termos reais. Tradução Marília Moschkovich. - São Paulo: nVersos, 2016.

FERRARI, Anderson. A "bicha banheirão" e o homossexual militante: grupos gays, educação e a construção do sujeito homossexual. 29ª Reunião anual da ANPED: Caxambu, 2006. FORTUNA, Carlos. Narrativas sobre a Metrópole centenária: Simmel, Hessel e Seabrook. Cadernos Metrópole, São Paulo, v.13. 26, 2012.

FOUCAULT, Michel. História da sexualidade. Vol. 1: A vontade de saber. 11a ed. Rio de Janeiro: Graal, 1988.

HAAL, Stuart. Identidade e diferença: uma introdução teórica e conceitual. In: SILVA, Tomaz T. (org.), HALL, Stuart, WOODWARD, Kathryn. Identidade e diferença: a perspectiva dos estudos culturais. - Petrópolis, RJ: Vozes, 2000.

HAESBAERT, Rogério. O mito da desterritorialização e as "regiões-rede". Anais do V Congresso Brasileiro de Geografia. Curitiba: AGB, p. 206-214, 1994.

HAESBAERT, Rogério. Des-caminhos e perspectivas do Território. In: RIBAS, A. D.; SPOSITO, E. S.; SAQUET, M. A. Território e Desenvolvimento: Diferentes abordagens Francisco Beltrão: Unioeste, 2004.

HEIDRICH, Álvaro Luiz, COSTA, Benhur Pinós da, PIRES, Cláudia Luisa Zeferino (organizadores). Maneiras de ler: geografia e cultura [recurso eletrônico] - Porto Alegre: Imprensa Livre: Compasso Lugar Cultura, 2013.

HEREK, Gregory M. Attitudes toward lesbians and gay men: A factor analytic study. The Journal of Homosexuality, v. 10, p. 39-51, 1984.

LOPES, Rosiane; GOMES, Luca Santoro. HIV E AIDS: Fatos e contextos relacionados com a Sexualidade. In: DIEHL, Alessandra. DENISE, Leite Vieira. Sexualidade: do prazer ao sofrer. São Paulo: 2013.

MAFFESOLI, Michel. A Contemplação do Mundo. Porto Alegre: Artes e Ofícios, 1995. MOITA, Gabriela. A patologização da diversidade sexual: Homofobia no discurso de 
clínicos. Revista Crítica de Ciências Sociais, n. 76, p. 53-72, 2006.

RAFFESTIN, Claude. Por uma Geografia do Poder. França. São Paulo: Ática, 1993.

RATZEL, Friedrich. Geografia do homem. São Paulo-SP: Ed. Ática, 1990. (Col. Grandes Cientistas Sociais.)

SACK, Robert D. Human territoriality: its theory and history. New York: Cambridge University Press, 1986

SAQUET, Marcos Aurélio. Os tempos e os territórios da colonização Italiana. Porto Alegre/RS: EST Edições, 2003 (2001).

SAQUET, Marcos Aurélio. Abordagens e Concepções de Território. São Paulo: Expressão Popular, 2005.

SANTOS, Milton. A cidade nos países subdesenvolvidos. Rio de Janeiro: Ed. Civilização Brasileira S.A., 1965.

SANTOS, Milton. Testamento Intelectual. São Paulo, Editora da Unesp, 2002

SOUZA, Marcelo José Lopes de. O Território: sobre espaço de poder, autonomia e desenvolvimento. In: CASTRO. I. E. de et al. (orgs.) Geografia: Conceitos e Temas. Rio de Janeiro: Bertrand Brasil, 1995

SOUZA, Marcelo José Lopes de. "Território" da divergência (e da confusão): em torno das imprecisas de um conceito fundamental. In: SAQUET, M. A.; SPOSITO, E. S. Território e territorialidades: teorias, processos e conflitos. São Paulo: Expressão Popular, 2009.

SWIDLER, Ann. Culture in action: symbols and strategies. American Sociological Review, n. 51, p. $273-286,1986$

SWIDLER, Arlene (Org.). Homosexuality and World Religions. Valley Forge, PA (USA): Trinity Press International, 1993.

TURRA, Nécio. Enterrado vivo: Identidade punk e território em Londrina. SP: Unesp, 2004.

PERES, William Siqueira; TOLEDO, Lívia Gonsalves. Dissidências Existenciais de Gênero: resistências e enfrentamentos ao biopoder. Psicologia Política. Vol. 11. No 22. p. 261-277. JUL. - DEZ. 2011.

MISKOLCI, Richard. Machos e Machos e Machos e Brothers: uma etnografia sobre o armário em relações homoeróticas criadas on-line. Estudos Feministas, Florianópolis, 21(1): 424, janeiro-abril/2013. 
UFSM. Observatório dos direitos humanos. Coletivo VOE apresenta primeiros dados de relatório sobre LGBTfobia em Santa Maria. Universidade Federal de Santa Maria. Publicado em 07/10/2019, 11h36. Atualizado 22/10/2019. Disponível em: < https://www.ufsm.br/pro-reitorias/pre/observatorio-de-direitos-humanos/2019/10/07/coletivovoe-apresenta-primeiros-dados-de-relatorio-sobre-lgbtfobia-em-santa-maria/>, acesso em: 24.06.2020.

Submetido: $25 / 06 / 2020$

Aprovado: 16/07/2020 